\title{
Insulin-like growth factor I: a predictor of long-term glucose abnormalities in patients with acute myocardial infarction
}

\author{
M. Wallander • K. Brismar • J. Öhrvik • L. Rydén • \\ A. Norhammar
}

Received: 23 May 2006 / Accepted: 20 June 2006 / Published online: 29 August 2006

(C) Springer-Verlag 2006

\begin{abstract}
Aims/hypothesis Low levels of IGF-I are associated with increased risk of cardiovascular disease and type 2 diabetes. The aim of this study was to investigate the IGF-I system in patients with acute myocardial infarction (AMI) without previously known diabetes.

Materials and methods One hundred and sixty-eight AMI patients were classified before hospital discharge by means of an OGTT as having NGT, IGT or newly detected type 2 diabetes. Age- and sex-matched subjects from the background population ( $n=185)$ served as the control group. The associations between fasting levels of IGF-I and IGF binding proteins 1 and 3 (IGFBP-1, IGFBP-3) and glucose metabolism during a follow-up period of 12 months were studied.

Results At hospital discharge, age-adjusted IGF-I (IGF-I SD) was significantly lower in patients with abnormal glucose tolerance (AGT=IGT or type 2 diabetes) compared with patients with NGT $(p=0.014)$ and control subjects $(p<0.001)$. IGF-I was strongly correlated with IGFBP-3 $(r=0.730, p<0.001)$, which was significantly lower in patients with AGT compared with patients with NGT $(p=0.009)$ and control subjects $(p<0.001)$. Fasting levels of IGFBP-1 did not differ significantly between patients with NGT and AGT or between patients and control

M. Wallander $(\bowtie) \cdot J$. Öhrvik $\cdot$ L. Rydén · A. Norhammar

Cardiology Unit N5:00, Department of Medicine,

Karolinska Institutet,

17176 Stockholm, Sweden

e-mail: marit.wallander@ki.se

K. Brismar

Endocrine and Diabetes Unit,

Department of Molecular Medicine and Surgery,

Karolinska Institutet,

Stockholm, Sweden
\end{abstract}

subjects. In a multiple logistic regression analysis in patients, IGF-I at hospital discharge was a significant predictor of AGT at discharge and after 12 months (adjusted odds ratio $0.29, p=0.022$, and adjusted odds ratio $0.29, p=0.034$, respectively).

Conclusions/interpretation Low levels of IGF-I may be a useful predictor of abnormal glucose metabolism in patients with AMI.

Keywords Acute myocardial infarction - Glucose tolerance IGF-I · IGFBP-1 · IGFBP-3 · Insulin-like growth factor
Abbreviations
AGT abnormal glucose tolerance
AMI acute myocardial infarction
GAMI Glucose Tolerance in Patients with Acute Myocardial Infarction
HOMA- homeostasis model assessment of insulin resis-
IR
hs-CRP high-sensitivity C-reactive protein
IGFBP IGF binding protein
IGF-I SD Age-standardised IGF-I score
IGI insulinogenic index
PAI1 plasminogen activator inhibitor 1

\section{Introduction}

Even at levels below the threshold for the diagnosis of diabetes, fasting and postprandial hyperglycaemia are risk factors for cardiovascular morbidity and mortality [1]. In recent years attention has been devoted to the increased risk of subsequent cardiovascular mortality and morbidity in patients with acute myocardial infarction (AMI) and 
disturbed glucose metabolism [2], a condition that is common in such patients [3, 4]. In previous studies we have seen that a substantial proportion of patients with AMI and glucose abnormalities do not have fasting blood glucose or $\mathrm{HbA}_{1 \mathrm{c}}$ above the threshold for type 2 diabetes and would consequently have been missed if not investigated by OGTT $[3,4]$.

Such observations make it of great importance to find novel and easily used markers of early stages of glucose abnormalities that may be helpful in future attempts to prevent cardiovascular events and mortality in AMI patients.

There is strong evidence that the IGF system plays an important role in glucose homeostasis [5] and low levels of IGF-I have recently been related to the development of type 2 diabetes [6]. Furthermore, clinical studies have shown that low levels of IGF-I and IGF binding proteins 1 and 3 (IGFBP-1 and IGFBP-3) are related to AMI or angiographically assessed coronary heart disease [7-10]. However, the findings are not consistent as previous studies also have shown that patients with coronary heart disease have increased levels of both IGF-I [11] and IGFBP-1 [12] and patients with low circulating IGF-I levels in combination with high IGFBP-3 levels had a significantly increased risk of developing ischaemic heart disease during a 15-year follow-up period [13].

Circulating IGF-I is primarily synthesised in the liver but also, in response to growth hormone, in every tissue, with insulin and amino acids as coactivators. IGF-I has a variety of functions in the regulation of growth and metabolism. The best characterised effects are linked to cell proliferation and accumulating knowledge suggests that IGF-I also is important for glucose homeostasis, lipolysis and protein oxidation. Glucometabolic effects of IGF-I include enhanced glucose uptake and improved insulin sensitivity [14]. The activity of IGF-I is regulated by its association with binding proteins, especially IGFBP-1 and IGFBP-3. IGFBP-3 binds IGF-I and functions together with the acidlabile subunit as a means of storing IGF-I in the circulation. IGFBP-1 has been described as the only acute regulator inhibiting the bioactivity of IGF-I in serum [15].

The primary aim of this study was to test the hypothesis that concentrations of IGF-I obtained early in the course of an AMI will identify lasting glucometabolic abnormalities. A secondary aim was to investigate the potential relationship between IGF-I, IGFBP-1, IGFBP-3 and future cardiovascular events.

\section{Subjects and methods}

A detailed description of the patients and control subjects from the Glucose Tolerance in patients with Acute
Myocardial Infarction (GAMI) study has been presented elsewhere $[3,16]$. Patients admitted for AMI were included if they fulfilled the following criteria: no previously known diabetes, baseline capillary blood glucose $<11.1 \mathrm{mmol} / \mathrm{l}$, serum creatinine $<200 \mu \mathrm{mol} / 1$ and age $\leq 80$ years. A total of 181 participants were enrolled, of whom 168 were characterised by means of an OGTT before hospital discharge as having NGT, IGT or type 2 diabetes.

A control group, described in detail elsewhere [16], was recruited by the use of local population registries that included all inhabitants of the two counties corresponding to the catchment areas of the participating hospitals. Five subjects matched for age and sex were randomly chosen as potential control subjects for each patient. The total number of control subjects was 185 persons without a prior diagnosis of diabetes mellitus or cardiovascular disease other than hypertension.

\section{Study protocol}

Blood glucose was measured upon arrival at the coronary care unit and each morning until the day of hospital discharge (day 4 or 5 ). $\mathrm{HbA}_{1 \mathrm{c}}$ was measured on the first morning following admission. On the day of hospital discharge a standardised OGTT (75 g glucose in $200 \mathrm{ml}$ water) was performed and blood glucose was measured at $0,15,30,60$ and $120 \mathrm{~min}$. Plasma concentrations of insulin and proinsulin were analysed in fasting samples taken on the first morning after admission and during the OGTT at 0,30 and $120 \mathrm{~min}$. In addition, IGFBP-1 was analysed before and $120 \mathrm{~min}$ after the glucose load. The following biochemical parameters were analysed in fasting conditions on day 2 and at the day of hospital discharge: IGF-I, IGFBP-1, IGFBP-3, total cholesterol, HDL- and LDL cholesterol, triglycerides, highly sensitive Creactive protein (hs-CRP) and cortisol. NEFA, plasminogen inhibitor activator 1 (PAI1) and fibrinogen were measured at discharge. Three and 12 months after hospital discharge, OGTT and all biochemical analyses were repeated together with collection of clinical data. All patients were followed regarding future cardiovascular events for a median period of 34 months.

The diagnosis of type 2 diabetes and IGT was based on the 1998 World Health Organization classification [17]. In the present report the presence of either of these two conditions is presented as abnormal glucose tolerance (AGT). AMI was defined according to the joint recommendations by the European Society of Cardiology and the American College of Cardiology [18].

Laboratory tests

Concentrations of IGF-I were determined in serum by RIA after separation of IGFs from IGFBPs by acid ethanol extraction and cryoprecipitation. To minimise interference 
by remaining IGFBPs, des(1-3)IGF-I was used as radioligand [19]. The intra- and interassay CVs were 4 and $11 \%$ respectively. IGFBP-1 concentrations in serum were determined by RIA according to the method of Povoa et al. [20]. The sensitivity of the RIA was $3 \mu \mathrm{g} / 1$ and the intra- and interassay CVs were 3 and 10\% respectively. IGFBP-3 was quantified in heparinised plasma using Immulite 2000 IGFBP-3 (DPC, Bad Nauheim, Germany), which is a solid-phase, enzyme-labelled chemiluminescent immunometric assay. The analytical sensitivity was $0.1 \mathrm{mg} / 1$ and the intra- and interassay CVs were 4 and $7 \%$, respectively. A detailed description of other laboratory methods has been presented elsewhere [16].

Calculations and statistical analyses

Because IGF-I decreases with age, a standardised IGF-I score (IGF-I SD) was calculated as follows:

IGF-I SD $=(\log [$ IGF-I $]+0.00625 \times$ age -2.555$) / 0.104$

The equation for IGF-I SD originates from the regression line of IGF-I values in 247 healthy adult subjects [21]. In Fig. 1 the IGF-I SD is converted back to the IGF-I scale by applying a common age (mean: 64 years) for the whole study population.

Insulin resistance, expressed as the homeostasis model assessment of insulin resistance (HOMA-IR), was calculated in the fasting condition as follows (1.13 converts blood glucose to plasma glucose and 6 converts pmol/1 to $\mathrm{mU} / \mathrm{l}$ ) according to Matthews et al. [22]:

HOMA-IR $=($ plasma insulin $\times$ blood glucose $\times 1.13)$

$$
/(22.5 \times 6)
$$

The insulinogenic index (IGI) was calculated as the difference between plasma insulin during the OGTT at 0 and $30 \mathrm{~min}(\Delta \mathrm{I} 30)$ divided by the difference between the corresponding glucose values $(\Delta \mathrm{G} 30)$. The adjusted IGI was corrected for insulin sensitivity by dividing it by HOMA-IR:

\section{Adjusted IGI $=(\Delta \mathrm{I} 30 / \Delta \mathrm{G} 30) / \mathrm{HOMA}-\mathrm{IR}$}

BMI was calculated as weight/height squared $\left(\mathrm{kg} / \mathrm{m}^{2}\right)$. Continuous variables are presented as median (quartile 1, quartile 3) and categorical variables as percentages. Differences between groups were compared using the $\chi^{2}$ test, Kruskal-Wallis test or Jonckheere-Terpstra test.

Differences in the profiles of IGF-I in patients and control subjects with respect to glucose tolerance categories were subjected to a non-parametric test for interactions based on aligned ranks (program written in Fortran) [23]. Spearman's rank correlation was calculated for pairs of continuous variables. Multiple logistic regression analyses were performed with the classification of AGT at discharge and after 12 months as dependent variables and all biochemical variables presented in Table 2, including age, sex and BMI, as candidate predictors. Predictors with a $p$ value $<0.2$ were entered into a best subset selection. All possible combinations of predictors were then fitted and the models were compared using the Akaike information criterion (AIC), which is -2 times the log likelihood plus a penalty function of two times the number of predictors in the model; the smaller the value of this criterion the better the model. The rationale behind this criterion is that if the only difference between two models is that a chance predictor has been included, the values of the AIC for the two models will not differ much and would rather tend to increase. The AIC is an approximate measure of prediction accuracy.

Cox proportional hazards regression was applied to investigate the relationship between variables from the IGF-I system and a composite endpoint consisting of cardiovascular death or a major cardiovascular event (stroke, re-infarction, severe heart failure). To limit the influence of extreme values, continuous variables were logtransformed prior to analysis if there was a skewed distribution. A two-sided $p$ value $<0.05$ was regarded as statistically significant. All analyses were made using SAS version 9.1.3 (SAS Institute, Cary, NC, USA).

Ethical considerations

The study was approved by the regional ethics committee at Karolinska Institute and all patients and control subjects provided written and oral informed consent.

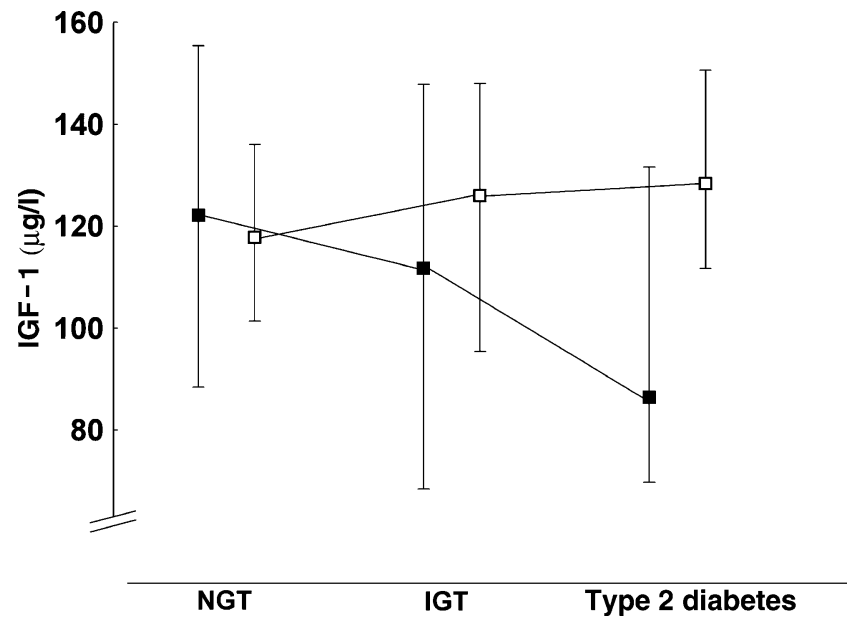

Fig. 1 Glucose tolerance profiles of age-adjusted IGF-I in patients and control subjects. Plots show the median (patients, filled squares; control subjects, empty squares) and interquartile range. $p$ value for interaction $<0.001$ 


\section{Results}

Clinical and biochemical characteristics

Pertinent clinical and biochemical characteristics of patients at hospital discharge and all control subjects are presented in Table 1. The patients were more frequently smokers, had higher fasting blood glucose, 2-h blood glucose, $\mathrm{HbA}_{1 \mathrm{c}}$, hs$\mathrm{CRP}$, triglycerides and proinsulin but lower HDL cholesterol and LDL cholesterol than the control subjects. A detailed discussion of these data has been published elsewhere [16].

At hospital discharge, 55 (33\%) patients were classified as having NGT while 113 (67\%) had AGT. Clinical and biochemical characteristics of the patients divided into glucose tolerance groups are presented in Table 2. There were no clinical differences between the patients except that those with AGT were older than those with NGT. None of the AGT patients received glucose-lowering drugs or insulin during the period of follow-up.

In patients with AGT, hs-CRP, NEFA, proinsulin and HOMA-IR were all significantly higher while beta cell function, measured as adjusted IGI, was lower compared with patients with NGT.

Among the control subjects, 120 (65\%) had NGT and 65 $(35 \%)$ AGT.

Insulin-like growth factor I

Patients had lower levels of IGF-I compared with control subjects (median [quartile 1, quartile 3]: 117.0 [75.0, 145.0] vs $122.0[99.0,143.0] \mu \mathrm{g} / 1, p=0.009)$. Table 3 contains all variables related to the IGF-I system in patients and control subjects and Table 4 contains unadjusted Spearman's rank correlations between IGF-I, IGFBP-1, IGFBP-3 and pertinent variables in patients.

Patients with AGT had lower levels of IGF-I compared with those with NGT $(p=0.002)$ and compared with control subjects, irrespective of glucose tolerance (NGT, $p<0.001$; AGT, $p=0.008)$. However, patients and control subjects with NGT did not differ in IGF-I levels. When dividing patients with AGT into those with IGT and those with type 2 diabetes and comparing these groups with patients with NGT, there was a significant difference between the three groups; the lowest IGF-I values were in the group with type 2 diabetes (median [quartile 1, quartile 3]: NGT, 128.0 $[93.0,154.0] \mu \mathrm{g} / \mathrm{l} ; \mathrm{IGT}, 99.0[70.0,144.5] \mu \mathrm{g} / \mathrm{l}$; type 2 diabetes, $90.5[67.0,125.0] \mu \mathrm{g} / 1 ; p<0.001)$. Figure 1 presents the glucose tolerance profiles of age-adjusted IGF-I levels in patients and control subjects, which were significantly different ( $p<0.001$ for the interaction).

Insulin-like growth factor binding proteins 1 and 3

Fasting levels of IGFBP-1 did not differ significantly between patients with NGT and AGT or between patients and control subjects (Table 3 ). The absolute decrease in IGFBP-1 during the OGTT was significantly smaller in patients with AGT than in the control subjects in general (NGT, $p<0.001$; AGT, $p=0.004$; Table 3 ), resulting in significantly higher 120-min IGFBP-1 levels in patients with AGT than in control subjects (NGT, $p<0.001$; AGT, $p=0.048$; Table 3).

Table 1 Pertinent clinical and biochemical characteristics of the patients at the time of hospital discharge and of the control subjects

\begin{tabular}{|c|c|c|c|}
\hline Variables & $\begin{array}{l}\text { Patients } \\
(n=181)\end{array}$ & $\begin{array}{l}\text { Control subjects } \\
(n=185)\end{array}$ & $p$ value \\
\hline Age (years) & $63.0(57.0,71.0)$ & $64.0(58.0,72.0)$ & 0.395 \\
\hline Sex (female; \%) & 31 & 31 & 0.932 \\
\hline Current smokers (\%) & 34 & 11 & $<0.001$ \\
\hline BMI $\left(\mathrm{kg} / \mathrm{m}^{2}\right)$ & $26.2(23.6,29.3)$ & $26.0(23.6,29.0)$ & 0.989 \\
\hline Fasting blood glucose $(\mathrm{mmol} / \mathrm{l})$ & $5.2(4.7,5.5)$ & $5.0(4.6,5.4)$ & 0.061 \\
\hline Blood glucose $120 \mathrm{~min}(\mathrm{mmol} / \mathrm{l})$ & $8.8(6.9,11.0)$ & $7.0(5.9,8.4)$ & $<0.001$ \\
\hline $\mathrm{HbA}_{1 \mathrm{c}}$ at admission $(\%)$ & $4.9(4.6,5.3)$ & $4.6(4.3,5.0)$ & $<0.001$ \\
\hline hs-CRP (mg/l) & $17.8(8.11,50.2)$ & $1.7(1.0,3.4)$ & $<0.001$ \\
\hline HDL cholesterol (pmol/l) & $1.0(0.9,1.2)$ & $1.2(1.0,1.5)$ & $<0.001$ \\
\hline LDL cholesterol (pmol/l) & $3.1(2.5,3.8)$ & $3.9(3.3,4.5)$ & $<0.001$ \\
\hline Triglycerides $(\mathrm{mmol} / \mathrm{l})$ & $1.9(1.6,2.6)$ & $1.2(0.9,1.6)$ & $<0.001$ \\
\hline NEFA $(\mathrm{mEq} / \mathrm{l})$ & $0.49(0.35,0.71)$ & $0.54(0.38,0.71)$ & 0.324 \\
\hline PAI1 activity (IU/ml) & $8.9(3.5,18.7)$ & $7.3(2.6,16.6)$ & 0.123 \\
\hline Insulin $(\mathrm{pmol} / \mathrm{l})$ & $53(35,84)$ & $47(32,74)$ & 0.126 \\
\hline Proinsulin (pmol/l) & $5.9(4.3,8.9)$ & $2.5(1.4,4.6)$ & $<0.001$ \\
\hline HOMA-IR (mU mmol/l) & $2.3(1.5,3.6)$ & $2.0(1.4,3.0)$ & 0.071 \\
\hline
\end{tabular}

Values are medians (quartile 1, quartile 3)

$p$ values based on $\chi^{2}$ or Kruskal-Wallis test 
Table 2 Clinical and biochemical characteristics of the patients with normal and abnormal glucose tolerance

\begin{tabular}{|c|c|c|c|}
\hline Variables & Normal glucose tolerance $(n=55)$ & Abnormal glucose tolerance $(n=113)$ & $p$ value \\
\hline \multicolumn{4}{|l|}{ Clinical characteristics } \\
\hline Age (years) & $60.0(54.0,67.0)$ & $64.0(57.0,72.0)$ & 0.007 \\
\hline Sex (female; \%) & 20 & 33 & 0.086 \\
\hline Current smokers (\%) & 13 & 33 & 0.355 \\
\hline BMI $\left(\mathrm{kg} / \mathrm{m}^{2}\right)$ & $26.0(23.1,28.3)$ & $26.8(24.0,29.7)$ & 0.133 \\
\hline \multicolumn{4}{|l|}{ Family history (\%) } \\
\hline Type 2 diabetes & 17 & 25 & 0.216 \\
\hline Coronary heart disease & 56 & 54 & 0.810 \\
\hline \multicolumn{4}{|l|}{ Previous diseases $(\%)$} \\
\hline Myocardial infarction & 13 & 22 & 0.146 \\
\hline Angina pectoris & 31 & 32 & 0.901 \\
\hline Hypertension (treated) & 31 & 34 & 0.723 \\
\hline Hyperlipidaemia (treated) & 15 & 17 & 0.701 \\
\hline \multicolumn{4}{|l|}{ Biochemical characteristics } \\
\hline Fasting blood glucose (mmol/l) & $4.8(4.5,5.3)$ & $5.3(4.8,5.7)$ & n.a. \\
\hline Blood glucose $120 \mathrm{~min}(\mathrm{mmol} / \mathrm{l})$ & $6.5(5.9,7.1)$ & $10.3(8.8,11.9)$ & n.a. \\
\hline $\mathrm{HbA}_{1 \mathrm{c}}$ at admission $(\%)$ & $4.8(4.5,5.2)$ & $5.0(4.6,5.3)$ & 0.168 \\
\hline hs-CRP (mg/l) & $12.7(5.3,28.0)$ & $23.0(9.4,65.2)$ & 0.002 \\
\hline Total cholesterol (pmol/1) & $5.5(4.6,6.0)$ & $5.0(4.4,5.8)$ & 0.168 \\
\hline HDL cholesterol (pmol/1) & $1.0(0.9,1.3)$ & $1.0(0.9,1.2)$ & 0.912 \\
\hline LDL cholesterol (pmol/l) & $3.3(2.6,3.9)$ & $3.0(2.5,3.6)$ & 0.305 \\
\hline Triglycerides $(\mathrm{mmol} / \mathrm{l})$ & $2.1(1.5,2.6)$ & $1.9(1.6,2.6)$ & 0.460 \\
\hline NEFA $(\mathrm{mEq} / \mathrm{l})$ & $0.39(0.30,0.61)$ & $0.57(0.36,0.73)$ & 0.010 \\
\hline PAI1 activity (IU/ml) & $6.4(3.1,14.4)$ & $10.4(4.0,20.9)$ & 0.106 \\
\hline Fibrinogen $(g / 1)$ & $5.1(4.3,6.3)$ & $5.4(4.6,7.0)$ & 0.207 \\
\hline Cortisol (nmol/l) & $486(408,609)$ & $476(395,602)$ & 0.848 \\
\hline Insulin $(\mathrm{pmol} / \mathrm{l})$ & $52(33,70)$ & $56(37,90)$ & 0.113 \\
\hline Proinsulin (pmol/l) & $4.9(3.9,6.8)$ & $6.8(4.6,9.3)$ & $<0.001$ \\
\hline HOMA-IR (mU mmol/l) & $2.07(1.34,2.71)$ & $2.53(1.52,3.97)$ & 0.024 \\
\hline Adjusted insulinogenic index $\left(1 / \mathrm{mmol}^{2}\right)^{\mathrm{a}}$ & $33.5(21.3,43.1)$ & $18.7(9.06,31.6)$ & $<0.001$ \\
\hline
\end{tabular}

Values are presented as median (quartile 1, quartile 3); $p$ values are based on the $\chi^{2}$ or Kruskal-Wallis test; if not stated otherwise, values were obtained at hospital discharge

n.a. Not applicable (used for classification)

${ }^{a}$ Adjusted insulinogenic index $=(\Delta \mathrm{I} 30 / \Delta \mathrm{G} 30) / \mathrm{HOMA}-\mathrm{IR}$

Fasting levels of IGFBP-3 were significantly lower in patients compared with control subjects (median [quartile 1, quartile 3]: $3.1[2.4,3.7]$ vs $3.7[3.7,3.2] \mathrm{mg} / 1, p<0.001)$.
Patients with AGT had lower levels of IGFBP-3 compared with those with NGT $(p=0.009)$ and with controls (NGT, $p<0.001$; AGT, $p<0.001$; Table 3).

Table 3 Variables from the IGF-I system in patients and controls divided into glucose tolerance groups

\begin{tabular}{|c|c|c|c|c|c|c|}
\hline \multirow[t]{2}{*}{ Variable } & \multicolumn{3}{|l|}{ Patients } & \multicolumn{3}{|l|}{ Control subjects } \\
\hline & NGT $(n=55)$ & $\operatorname{AGT}(n=113)$ & $p$ value $^{\mathrm{a}}$ & NGT $(n=120)$ & AGT $(n=65)$ & $p$ value $^{\mathrm{a}}$ \\
\hline IGF-I $(\mu \mathrm{g} / \mathrm{l})$ & $128.0(93.0,154.0)$ & $93.5(68.5,138.0)^{\mathrm{b}}$ & 0.002 & $122.0(100.0,143.0)$ & $124.0(90.0,149.0)^{\mathrm{b}}$ & 0.971 \\
\hline IGF-I SD & $-0.66(-2.00,0.35)$ & $-1.74(-3.00,-0.02)^{\mathrm{b}}$ & 0.014 & $-0.81,(-1.43,-0.21)$ & $-0.47(-1.53,0.22)^{\mathrm{b}}$ & 0.250 \\
\hline IGFBP-1 baseline $(\mu \mathrm{g} / \mathrm{l})$ & $18.0(10.0,28.0)$ & $20.0(12.0,31.0)$ & 0.400 & $16.0(10.0,26.0)$ & $19.0(12.0,26.0)$ & 0.345 \\
\hline 2-h IGFBP-1 $(\mu \mathrm{g} / \mathrm{l})$ & $10.0(5.0,17.0)$ & $11.5(7.0,19.0)^{\mathrm{b}}$ & 0.143 & $8.0(5.0,12.0)$ & $9.0(6.0,14.0)^{\mathrm{b}}$ & 0.155 \\
\hline 2-h IGFBP-1/IGFBP-1 baseline & $0.52(0.44,0.75)$ & $0.63(0.46,0.74)^{\mathrm{b}}$ & 0.218 & $0.50(0.43,0.58)$ & $0.50(0.44,0.62)^{\mathrm{b}}$ & 0.342 \\
\hline IGFBP-3 (mg/l) & $3.4(2.7,3.9)$ & $2.9(2.2,3.6)^{\mathrm{b}}$ & 0.009 & $3.6(3.2,4.2)$ & $3.8(3.1,4.3)^{\mathrm{b}}$ & 0.546 \\
\hline
\end{tabular}

Values are expressed as median (quartile 1, quartile 3); patient values were obtained at hospital discharge; $p$ values are based on the KruskalWallis test

${ }^{a} p$ value for the difference between glucose tolerance groups in patients and controls, respectively

${ }^{b} p<0.05$ for the difference between patients and controls in the same glucose tolerance category 


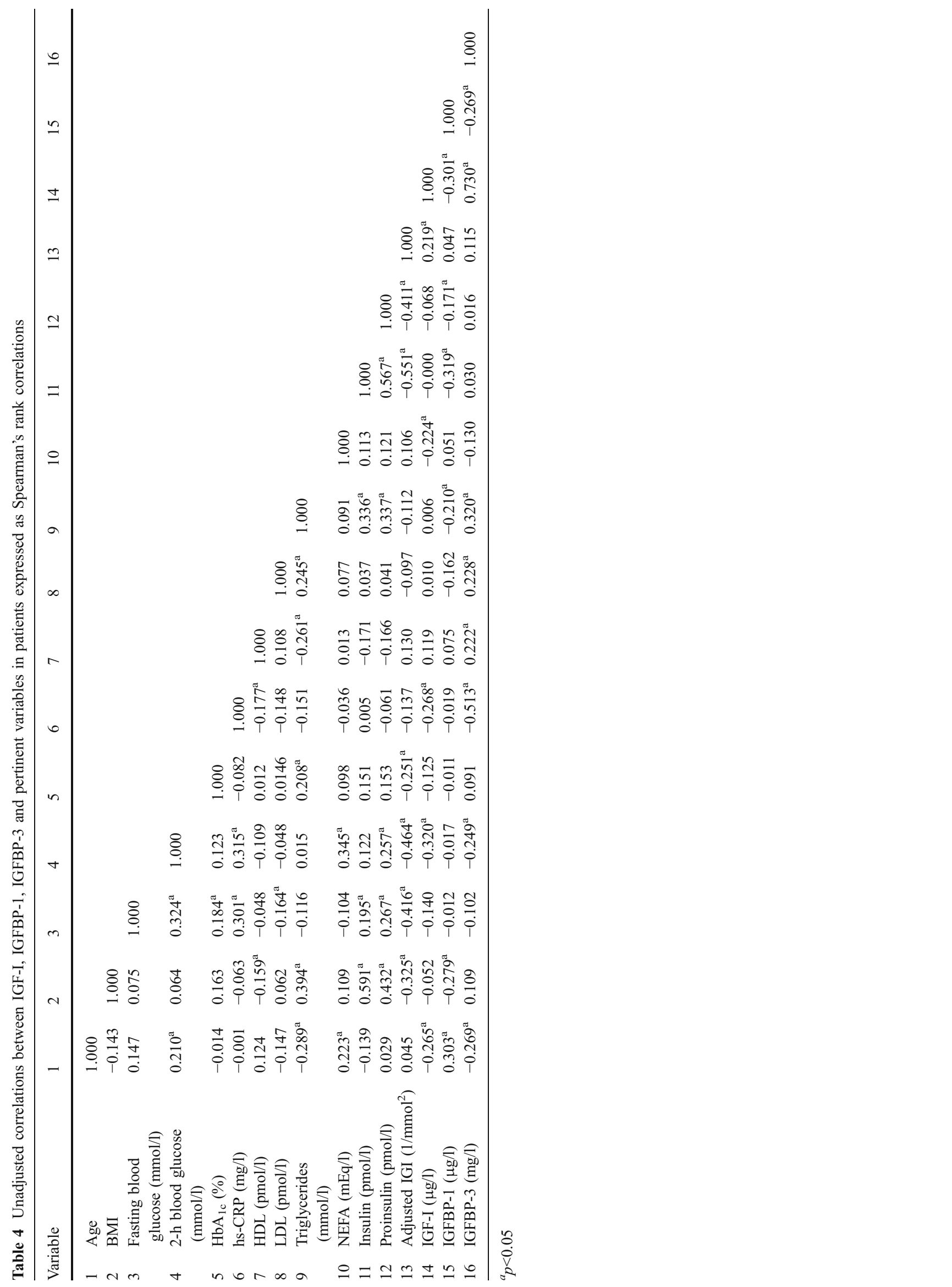


Prediction of abnormal glucose tolerance

Candidate predictors $(p<0.2)$ for AGT at discharge in order of significance were (univariate odds ratio $[95 \% \mathrm{CI}]$, $p$-value): fasting blood glucose, 2.8 [1.6-5.1], $p<0.001$; In IGF-I, 0.2 [0.1-0.5], $p=0.001$; ln hs-CRP, 1.5 [1.2-2.0], $p=0.002$; age, $1.1[1.0-1.1], p=0.005 ;$ In proinsulin, 2.5 [1.3-4.7], $p=0.006$; In HOMA-IR, 1.9 [1.1-3.2], $p=0.014$; In IGFBP-3, 0.2 [0.1-0.8], $p=0.018$; In NEFA 2.2 [1.1-4.1], $p=0.020 ; \ln$ insulin, $1.7[1.0-2.8], p=0.071$; female sex, 1.9 [0.9-4.2], $p=0.089 ; \mathrm{HbA}_{1 \mathrm{c}}, 1.7[0.9-3.1], p=0.097 ; \mathrm{ln}$ PAI1, 1.3 [0.9-1.7], $p=0.110$; and ln fibrinogen, $2.3[0.8$ 6.7], $p=0.138$.

The candidate predictors for AGT after 12 months in order of significance were: $\mathrm{HbA}_{1 \mathrm{c}}, 5.8$ [2.4-14.1], $p<0.001$; fasting blood glucose, 2.9 [1.5-5.7], $p=0.002$; In proinsulin, $2.8[1.3,5.9], p=0.006$; In IGF-I, $0.3[0.1-0.8], p=0.017 ; \ln$ triglycerides, $3.1[1.1-8.7], p=0.034 ;$ In HOMA-IR, 2.0 [1.1-3.6], $p=0.025 ;$ In PAI1, 1.4 [1.0-2.1], $p=0.041 ; \ln$ insulin, 1.8 [1.0-3.4], $p=0.059$; ln hs-CRP, 1.3 [1.0-1.7], $p=0.067$, BMI, $1.1[1.0-1.2], p=0.100 ;$ and $\ln$ NEFA, 1.8 [0.8-3.7], $p=0.136$.

The final models, which are presented in Table 5, represent those with the strongest predictive value. The replacement of any of these variables did not improve the predictive power. IGF-I at hospital discharge remained a significant predictor of AGT both at the time of hospital discharge and 12 months later $(\mathrm{OR}=0.29 ; p=0.022$ and $\mathrm{OR}=0.29 ; p=0.034$, respectively, Table 5). Other variables in the final models, in order of significance, were fasting blood glucose, NEFA, proinsulin (predictors for AGT at discharge), $\mathrm{HbA}_{1 \mathrm{c}}$ and triglycerides (predictors for AGT at 12 months).

Relationships to cardiovascular events

During the period of follow-up (median: 34 months) there were a total of 39 major cardiovascular events, including 12 cases of cardiovascular death [2]. Neither IGF-I, IGFBP-1 nor IGFBP-3 at hospital discharge could predict the occurrence of these events, while IGF-I on the first morning after admission presented a hazard ratio of $0.6(95 \% \mathrm{CI}$ : $0.3-1.2, p=0.133)$.

\section{Discussion}

The main finding in this study was that AMI patients with newly detected AGT have lower levels of IGF-I and IGFBP-3 compared with patients with NGT and controls with NGT or AGT and that IGF-I can be used to predict the subsequent glucometabolic state.

In the present study, in patients, IGF-I was inversely related to the 120-min post-load blood glucose and early
Table 5 Results of multiple logistic regression analyses

\begin{tabular}{|c|c|c|c|}
\hline Variables & Odds ratio & $95 \% \mathrm{CI}$ & $p$ value \\
\hline \multicolumn{4}{|l|}{ Prediction of AGT at discharge } \\
\hline Fasting blood glucose $(\mathrm{mmol} / \mathrm{l})$ & 2.93 & $1.39-6.17$ & 0.005 \\
\hline ln NEFA $(\mathrm{mEq} / \mathrm{l})$ & 3.01 & $1.26-7.18$ & 0.013 \\
\hline $\ln$ IGF-I $(\mu \mathrm{g} / \mathrm{l})$ & 0.29 & $0.10-0.83$ & 0.022 \\
\hline In proinsulin $(\mathrm{pmol} / \mathrm{l})$ & 2.11 & $0.98-4.59$ & 0.058 \\
\hline \multicolumn{4}{|l|}{ Prediction of AGT after 12 months } \\
\hline $\mathrm{HbA}_{1 \mathrm{c}}$ at admission $(\%)$ & 6.79 & $2.08-22.22$ & 0.002 \\
\hline ln triglycerides $(\mathrm{mmol} / \mathrm{l})$ & 7.05 & $1.67-29.83$ & 0.008 \\
\hline $\ln$ IGF-I $(\mu \mathrm{g} / 1)$ & 0.29 & $0.09-0.91$ & 0.034 \\
\hline
\end{tabular}

Odds ratios are for the classification of abnormal glucose regulation after an OGTT at discharge and after 12 months; if not stated otherwise, values were obtained at discharge; variables that were considered as candidate predictors in the multiple regression analyses (univariate $p$ value $<0.2$ ) but did not remain significant predictors in the final models were age, sex, BMI, hs-CRP, total, HDL and LDL cholesterol, PAI1, fibrinogen, cortisol, insulin and HOMA-IR

insulin secretion but not to fasting blood glucose. This supports the idea that IGF-I is related to the processes that regulate postprandial concentrations of glucose, such as first-phase insulin secretion and glucose uptake.

There was a difference between patients with AMI and normal or abnormal glucose tolerance, indicating that processes related to the acute event by itself are not the likely explanation for the decrease in IGF-I. This assumption is supported by IGF-I remaining lower among AGT patients 3 months after the infarction (median 120.0 vs $144.0 \mu \mathrm{g} / \mathrm{l}, p=0.015)$. Because of the loss of patients over time, the data at 3 months were less complete, which is the reason for basing this analysis on data obtained during the hospital phase of the study. Moreover, low levels of IGF-I at discharge predicted the classification of AGT both at discharge and after 12 months in multiple logistic regression models. Fasting blood glucose was a strong predictor of the outcome of the OGTT at discharge; $\mathrm{HbA}_{1 \mathrm{c}}$ did not add any predictive power to this model. In contrast, $\mathrm{HbA}_{1 \mathrm{c}}$ was the strongest predictor of AGT after 12 months whereas fasting blood glucose was not a significant predictor. Interestingly, IGF-I added predictive power to both the short- and the long-term model. Although other known risk factors for diabetes, such as NEFA, triglycerides and proinsulin, were included in the models, IGF-I was the only biochemical variable that remained stable in all models. Moreover, the best subset analyses, which were used to investigate the predictive values of all candidate predictors at the same time, revealed that IGF-I at discharge seemed to be a better predictor of AGT both at discharge and after 12 months compared with traditional risk factors, such as age, HDL cholesterol and LDL cholesterol, hs-CRP, BMI, insulin, proinsulin and HOMA-IR. 
In the present study, population-derived controls with AGT did not differ in IGF-I from controls with NGT. Likewise, patients with NGT had IGF-I values similar to those of controls with NGT.

The subdivision made in the present study of patients into groups with AGT and NGT is justified by the fact that the long-term prognosis as regards new cardiovascular events in the patients included in the present study was considerably better among those with NGT than those with either IGT or newly detected type 2 diabetes [2].

A previous evaluation of the present patients revealed that they had beta cell dysfunction [24]. It has been speculated that the combination of low IGF-I and decreased insulin function makes the patient more prone to developing AGT, causing a high postprandial glucose level [25] which has been shown to be a more apparent predictor of subsequent cardiovascular events than fasting glucose [26].

Another finding of the present study was that patients with AGT had lower levels of IGFBP-3 compared with patients with NGT and controls and that these levels correlated with IGF-I. This correlation was not surprising by itself since it is known that IGFBP-3 binds approximately $95 \%$ of total IGF-I in serum, increasing the half-life of IGF-I from a few minutes to $12-15 \mathrm{~h}$. It has been hypothesised that this binding stabilises IGF-I levels in serum, creating a pool of IGF-I available during periods of stress [14]. Previous studies have reported lower levels of IGFBP-3 both in patients with type 2 diabetes [27] and in patients with coronary heart disease [10]. In this context, our findings further emphasise the involvement of the IGF-I system in the pathogenesis of these conditions.

Furthermore, inhibition of IGFBP-1 during the OGTT, measured as the percentage decrease in IGFBP-1, was significantly lower in patients with AGT compared with controls. IGFBP-1, mainly produced in the liver, is inhibited by insulin [28]. Thus, the present findings indicate increased hepatic insulin resistance in patients with AMI and AGT [29].

The adjusted IGI, recently introduced as a simple index for beta cell secretory capacity obtained from the OGTT [30], corresponds to the first-phase insulin response to glucose ingestion adjusted for insulin resistance measured as HOMA-IR. In the present study, IGF-I was related to the adjusted IGI. Furthermore, IGF-I was related to NEFA, a finding which could partly explain the relationship between IGF-I and beta cell function, since increased levels of NEFA are known to have a direct toxic effect on the beta cells [31]. Moreover, many studies have previously shown that IGF-I seems to be important for the survival of beta cells [32].

Circulating levels of IGF-I, IGFBP-1 and IGFBP-3 have been proposed as risk factors for cardiovascular disease in large population studies $[9,13,33]$. In the present study,
IGFBP-1 and IGFBP-3 did not correlate to major cardiovascular events, and levels of IGF-I obtained on the first day after admission presented a non-significant trend towards a more dismal prognosis. However, the GAMI population represents a fairly small study $(n=181)$ of patients with early glucose abnormalities and consequently there is a limited number of events $(n=39)$. This limitation may hamper the possibility of predicting the value of IGF-I as a marker of prognosis, because of low power. Accordingly, the survival analysis from the present study needs confirmation in a larger population, possibly of AMI patients.

A limitation of IGF-I as a predictor is the wide normal range and a strong relationship to age, creating difficulties in setting limits for the definition of abnormally low levels. To overcome these difficulties we recommend the use of the standardised IGF-I (IGF-I SD) as presented in this report.

In conclusion, this study provides evidence supporting the importance of IGF-I for glucose homeostasis in patients with AMI. Furthermore, AMI patients with AGT have a lower level of inhibition of IGFBP-1 during an OGTT compared with controls, which could be interpreted as increased hepatic insulin resistance.

IGF-I may be a clinically useful tool for the glucometabolic classification of patients with AMI, allowing early institution of therapeutic modalities directed towards the metabolic disturbance. It deserves further evaluation as regards its prognostic implications.

Acknowledgements The authors are grateful to A. Larsson, E. Sandberg and T. Gustafsson for performing laboratory analyses. This study was supported by AFA Insurance, the Swedish Heart-Lung Foundation, King Gustaf V, Queen Victoria Foundation, the Family Erling-Persson Foundation and Signe and Olof Wallenius Foundation. These grants were totally unrestricted and unconditional.

\section{References}

1. Coutinho M, Gerstein HC, Wang Y, Yusuf S (1999) The relationship between glucose and incident cardiovascular events. A metaregression analysis of published data from 20 studies of 95,783 individuals followed for 12.4 years. Diabetes Care 22:233-240

2. Bartnik M, Malmberg K, Norhammar A, Tenerz A, Ohrvik J, Ryden L (2004) Newly detected abnormal glucose tolerance: an important predictor of long-term outcome after myocardial infarction. Eur Heart J 25:1990-1997

3. Norhammar A, Tenerz A, Nilsson G et al (2002) Glucose metabolism in patients with acute myocardial infarction and no previous diagnosis of diabetes mellitus: a prospective study. Lancet 359:2140-2144

4. Bartnik M, Ryden L, Ferrari R et al (2004) The prevalence of abnormal glucose regulation in patients with coronary artery disease across Europe. The Euro Heart Survey on diabetes and the heart. Eur Heart J 25:1880-1890

5. Lewitt MS (1994) Role of the insulin-like growth factors in the endocrine control of glucose homeostasis. Diabetes Res Clin Pract $23: 3-15$ 
6. Sandhu MS, Heald AH, Gibson JM, Cruickshank JK, Dunger DB, Wareham NJ (2002) Circulating concentrations of insulin-like growth factor-I and development of glucose intolerance: a prospective observational study. Lancet 359:1740-1745

7. Laughlin GA, Barrett-Connor E, Criqui MH, Kritz-Silverstein D (2004) The prospective association of serum insulin-like growth factor I (IGF-I) and IGF-binding protein-1 levels with all cause and cardiovascular disease mortality in older adults: the Rancho Bernardo Study. J Clin Endocrinol Metab 89:114-120

8. Spallarossa P, Brunelli C, Minuto F et al (1996) Insulin-like growth factor-I and angiographically documented coronary artery disease. Am J Cardiol 77:200-202

9. Heald AH, Siddals KW, Fraser W et al (2002) Low circulating levels of insulin-like growth factor binding protein-1 (IGFBP-1) are closely associated with the presence of macrovascular disease and hypertension in type 2 diabetes. Diabetes 51:2629-2636

10. Schuler-Luttmann S, Monnig G, Enbergs A et al (2000) Insulinlike growth factor-binding protein-3 is associated with the presence and extent of coronary arteriosclerosis. Arterioscler Thromb Vasc Biol 20:E10-E15

11. Ruotolo G, Bavenholm P, Brismar K et al (2000) Serum insulin-like growth factor-I level is independently associated with coronary artery disease progression in young male survivors of myocardial infarction: beneficial effects of bezafibrate treatment. J Am Coll Cardiol 35:647-654

12. Harrela M, Qiao Q, Koistinen R et al (2002) High serum insulin-like growth factor binding protein-1 is associated with increased cardiovascular mortality in elderly men. Horm Metab Res 34:144-149

13. Juul A, Scheike T, Davidsen M, Gyllenborg J, Jorgensen T (2002) Low serum insulin-like growth factor $\mathrm{I}$ is associated with increased risk of ischemic heart disease: a population-based case-control study. Circulation 106:939-944

14. Jones JI, Clemmons DR (1995) Insulin-like growth factors and their binding proteins: biological actions. Endocr Rev 16:3-34

15. Lewitt MS, Denyer GS, Cooney GJ, Baxter RC (1991) Insulinlike growth factor-binding protein-1 modulates blood glucose levels. Endocrinology 129:2254-2256

16. Bartnik M, Malmberg K, Hamsten A et al (2004) Abnormal glucose tolerance - a common risk factor in patients with acute myocardial infarction in comparison with population-based controls. J Intern Med 256:288-297

17. Alberti KG, Zimmet PZ (1998) Definition, diagnosis and classification of diabetes mellitus and its complications. Part 1: diagnosis and classification of diabetes mellitus provisional report of a WHO consultation. Diabet Med 15:539-553

18. ESC (2000) Myocardial infarction redefined - a consensus document of The Joint European Society of Cardiology/American College of Cardiology Committee for the redefinition of myocardial infarction. Eur Heart J 21:1502-1513

19. Bang P, Eriksson U, Sara V, Wivall IL, Hall K (1991) Comparison of acid ethanol extraction and acid gel filtration prior to IGF-I and IGF-II radioimmunoassays: improvement of determinations in acid ethanol extracts by the use of truncated IGF-I as radioligand. Acta Endocrinol (Copenh) 124:620-629
20. Povoa G, Roovete A, Hall K (1984) Cross-reaction of serum somatomedin-binding protein in a radioimmunoassay developed for somatomedin-binding protein isolated from human amniotic fluid. Acta Endocrinol (Copenh) 107:563-570

21. Hilding A, Brismar K, Degerblad M, Thoren M, Hall K (1995) Altered relation between circulating levels of insulin-like growth factor-binding protein-1 and insulin in growth hormone-deficient patients and insulin-dependent diabetic patients compared to that in healthy subjects. J Clin Endocrinol Metab 80:2646-2652

22. Matthews DR, Hosker JP, Rudenski AS, Naylor BA, Treacher DF, Turner RC (1985) Homeostasis model assessment: insulin resistance and beta-cell function from fasting plasma glucose and insulin concentrations in man. Diabetologia 28:412-419

23. Öhrvik J (2002) Nonparametric methods in the two-way layout. Chiang Mai J Sci 29:103-115

24. Wallander M, Bartnik M, Efendic S et al (2005) Beta cell dysfunction in patients with acute myocardial infarction but without previously known type 2 diabetes: a report from the GAMI study. Diabetologia 48:2229-2235

25. Janssen JA, Lamberts SW (2002) The role of IGF-I in the development of cardiovascular disease in type 2 diabetes mellitus: is prevention possible? Eur J Endocrinol 146:467-477

26. DECODE (2001) Glucose tolerance and cardiovascular mortality: comparison of fasting and 2-hour diagnostic criteria. Arch Intern Med 161:397-405

27. Bang P, Brismar K, Rosenfeld RG (1994) Increased proteolysis of insulin-like growth factor-binding protein-3 (IGFBP-3) in noninsulin-dependent diabetes mellitus serum, with elevation of a 29kilodalton $(\mathrm{kDa})$ glycosylated IGFBP-3 fragment contained in the approximately 130 - to $150-\mathrm{kDa}$ ternary complex. J Clin Endocrinol Metab 78:1119-1127

28. Brismar K, Fernqvist-Forbes E, Wahren J, Hall K (1994) Effect of insulin on the hepatic production of insulin-like growth factorbinding protein-1 (IGFBP-1), IGFBP-3, and IGF-I in insulindependent diabetes. J Clin Endocrinol Metab 79:872-878

29. Brismar K, Lewitt MS (2004) The IGF and IGFBP system in insulin resistance and diabetes mellitus. In: Houston MS, Holly JMP, Feldman EL (eds) IGF and nutrition in health and disease. Humana, Totowa, pp 251-270

30. Jensen CC, Cnop M, Hull RL, Fujimoto WY, Kahn SE (2002) Beta-cell function is a major contributor to oral glucose tolerance in high-risk relatives of four ethnic groups in the U.S. Diabetes 51:2170-2178

31. Boden G, Shulman GI (2002) Free fatty acids in obesity and type 2 diabetes: defining their role in the development of insulin resistance and beta-cell dysfunction. Eur J Clin Invest 32(Suppl 3): $14-23$

32. Vaessen N, Heutink P, Janssen JA et al (2001) A polymorphism in the gene for IGF-I: functional properties and risk for type 2 diabetes and myocardial infarction. Diabetes 50:637-642

33. Leinonen ES, Salonen JT, Salonen RM et al (2002) Reduced IGFBP-1 is associated with thickening of the carotid wall in type 2 diabetes. Diabetes Care 25:1807-1812 